\title{
Enhancement of Activity of PtRu Nanoparticles Towards Oxidation of Ethanol by Supporting on Poly (diallyldimethylammonium)-Functionalized Carbon Nanotubes and Modification with Phosphomolybdate
}

\author{
Piotr Juliusz Barczuk • Adam Lewera • \\ Katarzyna Skorupska $\cdot$ San Ping Jiang • \\ Changming Li $\cdot$ Pawel J. Kulesza
}

Received: 2 September 2010 /Accepted: 30 November 2010 /Published online: 15 December 2010

(C) The Author(s) 2010. This article is published with open access at Springerlink.com

\begin{abstract}
A new concept of fabrication, immobilization, and distribution of bimetallic PtRu nanoparticles leading to enhancement of the electrocatalytic oxidation of ethanol is proposed. The approach utilizes poly (diallyldimethylammonium chloride), PDDA, to functionalize multi-walled carbon nanotubes (MWCNTs) and to produce a novel support for synthesized PtRu nanoparticles as well as further modification of the catalytic surfaces with ultra-thin layers of phosphododecamolybdate $\left(\mathrm{PMo}_{12} \mathrm{O}_{40}{ }^{3-}\right)$. Remarkable increases of electrocatalytic currents measured under voltammetric and chronoamperometric conditions have been observed.
\end{abstract}

\footnotetext{
P. J. Barczuk · A. Lewera $\cdot$ K. Skorupska $\cdot$ P. J. Kulesza $(\bowtie)$ Department of Chemistry, University of Warsaw,

Pasteura 1,

02-093 Warsaw, Poland

e-mail: pkulesza@chem.uw.edu.pl

K. Skorupska

Institute for Solar Fuels and Energy Storage Materials,

Helmholtz Center Berlin for Materials and Energy,

Glienicker Str. 100,

Berlin 14109, Germany

S. P. Jiang $(\bowtie)$

Curtin Centre for Advanced Energy Science and Engineering, Department of Chemical Engineering,

Curtin University of Technology,

Perth, WA 6845, Australia

e-mail: sjiang@curtin.edu.au

C. Li

School of Chemical and Biomedical Engineering,

Nanyang Technological University,

50 Nanyang Avenue,

Singapore 639798, Singapore

Springer

Parallel experiments performed with use of commercial $\mathrm{PtRu}$ nanoparticles confirm existence of enhancement effects originating from application of PDDA-modified MWCNTs and phosphomolybdate.

Keywords Electrocatalysis $\cdot$ Ethanol oxidation $\cdot$ Bimetallic PtRu nanoparticles $\cdot$ Carbon nanotubes $\cdot$ Poly (diallyldimethylammonium chloride) Polyoxometallate

\section{Introduction}

There has been growing recent interest in the direct ethanol fuel cell technology as an alternative to the more established methanol analogs. In this respect, slow kinetic of electrooxidation of ethanol under conditions of operation of low-temperature fuel cells is one of the major limiting factors [1-3]. Electrooxidation of ethanol is certainly a much more complex process than oxidation of methanol because it requires breaking of $\mathrm{C}-\mathrm{C}$ bonds followed by removal of $\mathrm{CO}$ poisoning species (adsorbates). In addition to a serious problem of poisoning of the catalytic interface, the appearance of acetaldehyde and acidic acid as undesirable intermediates remains a crucial limiting factor in the development and commercialization of ethanol fuel cells. Several bi- and tri-metallic platinum-based catalysts were proposed to solve or minimize the above problems [4-8], but their utilization is still a kind compromise between partial activation and blocking of active sites on nanostructured platinum surfaces.

The currently considered most active catalytic materials for electrooxidation of ethanol are platinum-based nanoalloys with tin or ruthenium. Although systems utilizing 
carbon supported PtSn nanoparticles are often viewed as the most efficient catalysts [9-12], the limited stability of tin complicates their long-term application in real ethanol fuel cells. Therefore, we consider here the bimetallic PtRu system characterized by superior stability and reasonable activity towards electrooxidation of ethanol as an attractive object for further investigations and modifications.

The enhanced activity of bimetallic systems, such as $\mathrm{PtRu}$ or PtSn, over platinum alone is mainly due to the socalled bifunctional mechanism in which the second metal provides the surface active $-\mathrm{OH}$ groups capable of oxidation of the reaction by-products (mainly $\mathrm{CO}$ molecules) otherwise strongly adsorbing and passivating $\mathrm{Pt}$ surface [13-16].

Due to the high cost of the catalytic materials that include electrocatalysts for fuel cells, it is important to utilize appropriate carriers, supports, or matrices capable of enhancing the systems' catalytic activities. At present, nanostructured carbon (Vulcan) is the most popular carrier for catalytic noble metal nanoparticles of importance to fuel cell research. Recent studies clearly show that application of carbon nanotubes as carriers may result even in higher electrocatalytic activities in comparison to conventional carbon nanoparticles. But, to achieve this goal, graphene surfaces of carbon nanotubes need to be chemically modified or functionalized [17]. Properly functionalized MWCNTs not only assure physical separation and large dispersion of reactive sites at the catalytic interface but they also act as rigid templates for well-shaped and uniformly sized noble metal nanoparticles [17].

In the present work, we have elucidated the influence of supports composed of the poly(diallyldimethylammonium chloride)/PDDA functionalized multi-walled carbon nanotubes (MWCNTs) and Keggin-type heteropolymolybdate (phosphododecamolybdate, $\mathrm{PMo}_{12} \mathrm{O}_{40}{ }^{3-}$ or $\mathrm{PMo}_{12}$ ) modifying agent on catalytic activity of the PtRu nanoparticles during electrooxidation of ethanol. With respect to use of $\mathrm{PMo}_{12}$, we have referred to numerous examples in the literature [18-22] demonstrating electrocatalytic properties of polyoxometallates. In particular, it was reported that modification of PtSn or PtRu catalytic nanoaprticles with ultra-thin layers of $\mathrm{PMo}_{12}$ led to the enhancement of their activities during oxidation of ethanol [23]. To fabricate novel multifunctional composite catalytic nanostructures material with even more pronounced electrocatalytic properties towards electrooxidation of ethanol, we combine here advantages coming from the modification of Ptbased nanoparticles with polyoxometallates [24-26] with a unique concept of the synthesis of nanoparticles on the polymer-functionalized MWCNTs [17]. Our electrochemical studies are supported with transmission electron microscopic investigations and high resolution XPS measurements.

\section{Experimental}

\section{Materials}

All chemicals were commercial materials of analytical grade purity. The reagents and materials used were: PtRu nanoparticles (ratio 1:1, Alfa Aesar), phospododecamolybdic acid (Aldrich), ethanol (Fluka), multi-walled carbon nanotubes, ( diameter $20-30 \mathrm{~nm}$, SYST Integration PTE LTD), hexachloroplatinic (IV) acid $\left(\mathrm{H}_{2} \mathrm{PtCl}_{6}\right.$, SigmaAldrich), potassium chloride (Aldrich), ethylene glycol (Fluka), $\mathrm{H}_{2} \mathrm{SO}_{4}$, poly(diallyldimethylammonium chloride) (20 wt. $\%$ in water, $\mathrm{MW}=5,000-40,000$, Sigma-Aldrich), and a Nafion solution ( $5 \%$ in isopropanol).

Solutions were prepared using doubly distilled and subsequently deionized (Millipore Milli-Q) water. Argon was used to deaerate the solutions and to keep air-free atmosphere over the solution during the measurements.

\section{Functionalization of MWCNTs by PDDA}

MWCNTs were functionalized with PDDA polyelectrolyte as reported earlier [27]. MWCNTs $(100 \mathrm{mg})$ were ultrasonically suspended in deionized water $(400 \mathrm{~mL})$ in the presence of PDDA (0.5 wt.\%) and $\mathrm{KCl}(1 \mathrm{wt} . \%)$ to yield a stable suspension of nanotubes. The suspension was filtrated through a nylon membrane (pore size $0.2 \mu \mathrm{m}$ ), washed several times to remove excess PDDA and $\mathrm{KCl}$, and then dried in a vacuum oven at $70{ }^{\circ} \mathrm{C}$ for $24 \mathrm{~h}$.

Modification of the Commercial PtRu Nanoparticles with $\mathrm{H}_{3} \mathrm{PMo}_{12} \mathrm{O}_{40}$

Preparation of the $\mathrm{PMo}_{12}$-modified PtRu nanoparticles was done as follows: $5.5 \mathrm{mg}$ of Pt nanoparticles was dispersed within $400 \mu \mathrm{l}$ of aqueous $5 \mathrm{mmol} \mathrm{dm}{ }^{-3} \mathrm{H}_{3} \mathrm{PMo}_{12} \mathrm{O}_{40}$. The suspension was subsequently sonicated for $24 \mathrm{~h}$ and, later, centrifuged. Then, supernatant solution was replaced with fresh heteropolyacid solution, and the above procedure was repeated three to four times to produce a stable colloidal suspension.

\section{Synthesis of PtRu Nanoparticles on MWCNTs}

Synthesis of the PtRu nanoparticles on PDDA-functionalized MWCNTs was done as follows: $30 \mathrm{mg}$ of PDDA-MWCNTs were mixed with an approximate amount of $\mathrm{H}_{2} \mathrm{PtCl}_{6}$ and $\mathrm{RuCl}_{3}$ (at a molar ratio of Pt to $\mathrm{Ru} 1: 1$ ) in ethylene glycol solution in a beaker under ultrasonication. The beaker was placed in a microwave oven and heated for $2 \mathrm{~min}$. The solution changed from light yellow to dark brown, indicating the reduction and formation of PtRu nanoparticles on MWCNTs. The solution was then filtered using a nylon 
filter membrane and washed; the filtration was repeated several times. The PtRu electrocatalysts obtained on PDDAfunctionalized MWCNTs (PtRu/PDDA/MWCNTs) were dried in a vacuum oven at $70{ }^{\circ} \mathrm{C}$ for $24 \mathrm{~h}$. Polyoxometallate $\left(\mathrm{PMo}_{12}\right)$ was introduced into the PtRu/PDDA/MWCNTs system according to the procedure described earlier [23] for stabilization of commercial PtRu nanoparticles.

\section{Characterization}

The morphology of catalytic particles was monitored using a HITACHI HD2700 transmission electron microscope (TEM) operating at voltage $200 \mathrm{kV}$. Samples for TEM measurements were prepared by placing of colloidal solutions of nanoparticles on Formvar Film (Agar Scientific) grids and subjecting them to drying ( 400 mesh $\mathrm{Cu}$ ).

All electrochemical measurements were performed in a three electrodes configuration using Autolab workstation. The reference electrode was the $\mathrm{K}_{2} \mathrm{SO}_{4}$ saturated $\mathrm{Hg}_{2} \mathrm{SO}_{4}$ electrode; and a platinum foil was used as a counter electrode. All potentials have been recalculated and expressed versus the reversible hydrogen electrode.

\section{XPS Measurements}

XPS experiments were performed on commercially available unsupported (csrbon-free) PtRu nanoparticles (Alfa Aesar), in order to avoid overlapping between $\mathrm{C} 1 \mathrm{~s}$ and $\mathrm{Ru}$ $3 \mathrm{~d}$ signals $[28,29]$. The XPS apparatus consisted of hemispherical energy analyser PHOIBOS 100, HSA 3500 Power Supply and X-ray Source xR50 (all made by SPECS GmbH). Unmodified nanoparticles were deposited on a gold disk, used as a XPS holder, from pure water suspension (no Nafion used). A droplet of the nanoparticle suspension in water was deposited on the gold holder and left to dry in ambient atmosphere. In a case of measurements involving polyoxometallate-modified nanoparticles, the procedure utilized a suspension of nanoparticles in $5 \mathrm{mmol} \mathrm{dm}{ }^{-3} \mathrm{PMo}_{12}$ water solution. A droplet of this suspension was subsequently deposited on the gold XPS holder and dried. The deposit was rinsed with water for $5 \mathrm{~min}$ and dried prior to XPS experiment. Such treatment assured full removal of all of the heteropolyacid that was not attached to the nanoparticle surface.

\section{Results and Discussion}

Modification of Commercial PtRu Nanoparticles:

Physicochemical Characterization

We have utilized commercial PtRu nanoparticles modified (stabilized) with $\mathrm{PMo}_{12}$ to comment on the possible enhancement effect originating from the presence of a modifying agent at the catalytic interface. The positive role of phosphododecamolybdic acid in electrocatalysis was demonstrated in our previous works [21,23]. Voltammetric responses of PtRu system (a) before and (b) after stabilization with $\mathrm{PMo}_{12}$ are shown in Fig. 1 (solid lines). A cyclic voltammogram recorded for the bare system corresponds to the typical response of PtRu catalyst [13]. Indeed, its behavior is characterized by the lack of welldefined surface processes in the double-layer region [30]. After introducing the surface-adsorbed $\mathrm{PMo}_{12}$-modifying agent, we can observe some changes in the electrochemical characteristics of the investigated system. This modification results in increase of the overall electrocatalytic surface and in appearance of some peaks corresponding to the sequential reversible two-electron redox processes taking place in the potential region characteristic of oxidation/reduction reaction of phosphododecamolybdate [31]. Unlike the electrochemical behavior of $\mathrm{PMo}_{12}$ adsorbed on the carbon substrates, phosphododecamolybdate immobilized on noble metal nanoparticles is characterized by overlapping peaks, and it produces broad peak signals, namely an anodic peak at ca. $0.1 \mathrm{~V}$ and a quasi-reversible system with anodic and cathodic peak potentials at 0.45 and $0.4 \mathrm{~V}$, respectively. This observation corresponds to the previous investigations [23]. To change morphology and to further increase electrochemical surface, we have dispersed $\mathrm{PMo}_{12}$-modi-

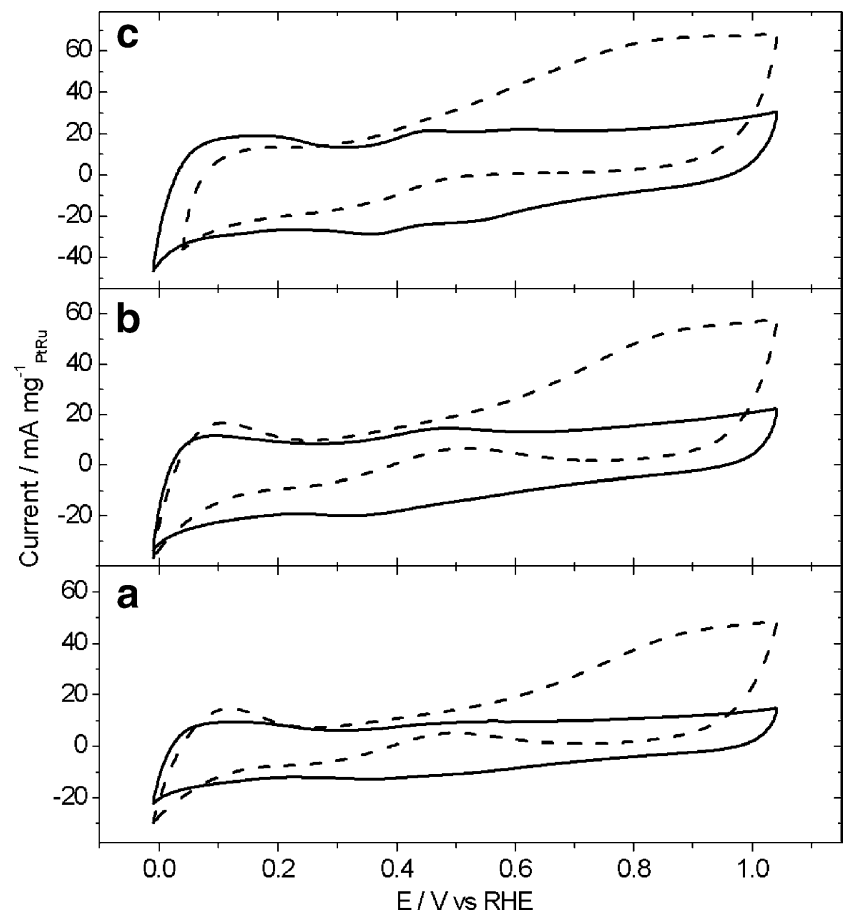

Fig. 1 Cyclic voltammograms of PtRu catalysts: pure (a), stabilized with $\mathrm{PMo}_{12}$ (b), stabilized with PMo12 and additionally supported onto PDDA-MWCNTs (c), recorded in $0.5 \mathrm{~mol} \mathrm{dm}{ }^{-3} \mathrm{H}_{2} \mathrm{SO}_{4}$ (solid lines) and following addition of $0.5 \mathrm{~mol} \mathrm{dm}^{-3}$ ethanol (dashed lines) 
fied PtRu nanoparticles $\left(\mathrm{PtRu} / \mathrm{PMo}_{12}\right)$ on carbon nanotubes. The use of the MWCNTs was preceded by their functionalization with PDDA according to the procedure described in the experimental section. In accordance to the previous reports [32], PDDA-functionalized MWCNTs exhibit desirable properties as carriers or supports for dispersed noble metal catalytic centers. The presence of the PDDA should not only to enhance activity of the carbon substrate but also to produce well-defined multicomponent system. In particular, PtRu nanoparticles modified with negatively charged $\mathrm{PMo}_{12}$ are expected to interact electrostatically with positively charged PDDAfunctionalized MWCNTs. Thus, the assembled PtRu nanoparticles should be stabilized and largely dispersed. The cyclic voltammetric behavior of such system is shown in Fig. 1, Curve c (solid line).

Upon assembling $\mathrm{PtRu} / \mathrm{PMo}_{12}$ nanoparticles onto PDDA-functionalized MWCNTs, the system has been investigated using transmission electron microscopy to
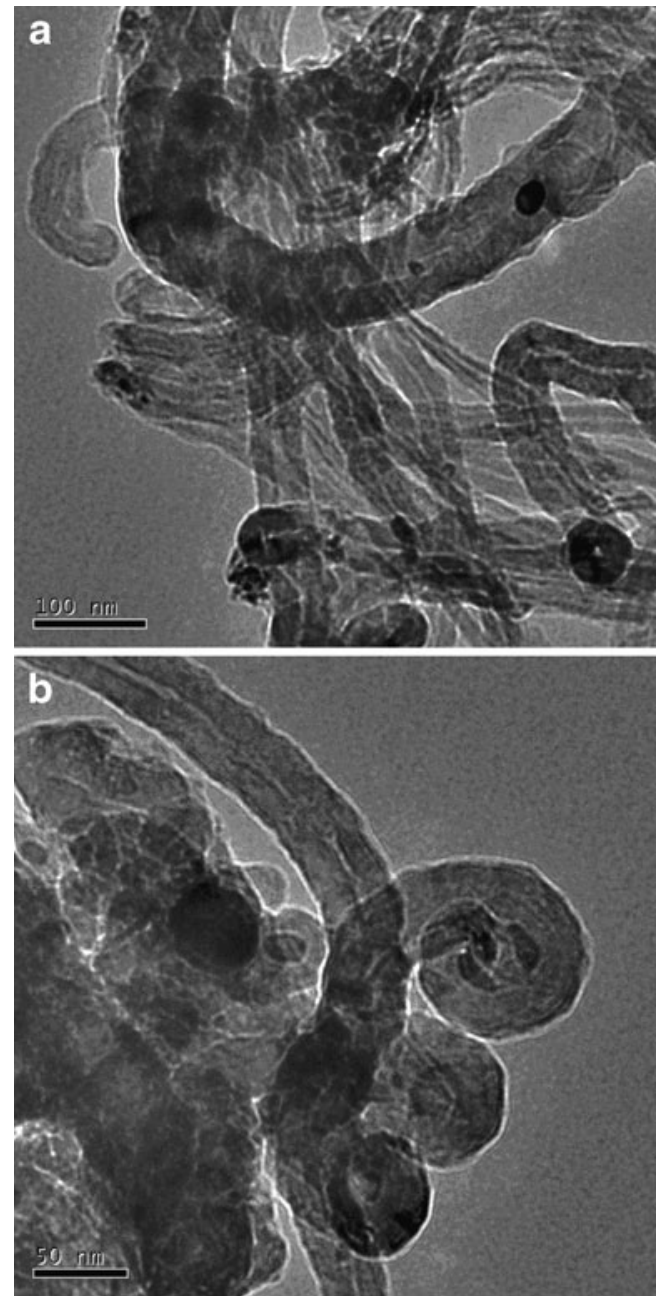

Fig. 2 a, b TEM images of $\mathrm{PMo}_{12}$ stabilized PtRu nanoparticles assembled onto PDDA-MWCNTs support
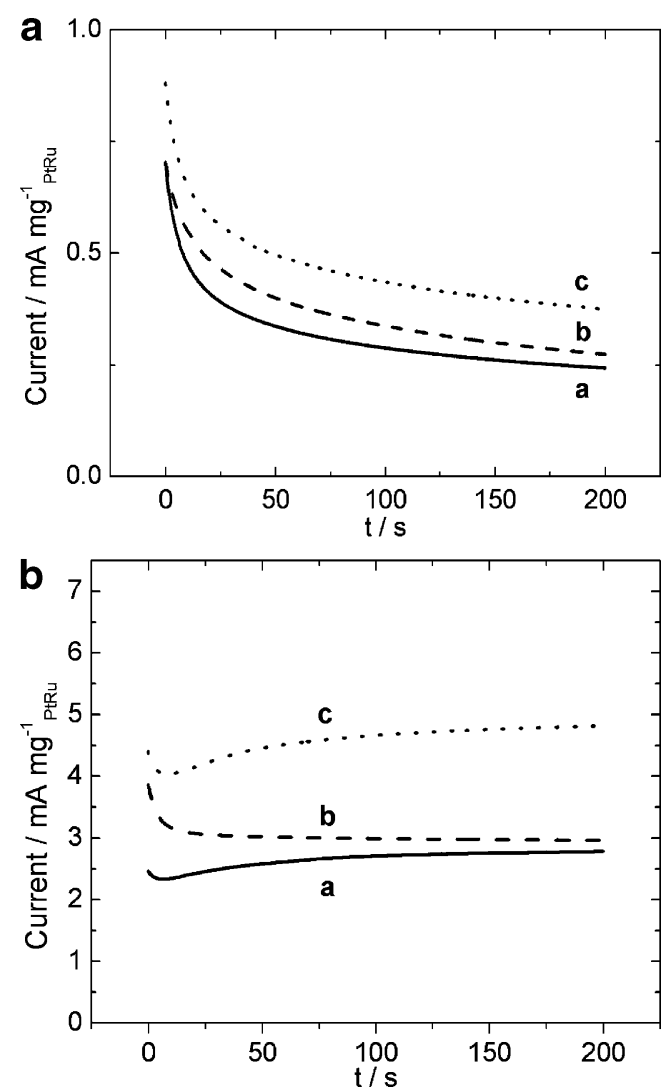

Fig. 3 Chronoamperometric electrooxidation of ethanol $\left(0.5 \mathrm{~mol} \mathrm{dm}^{-3}\right.$ solution) recorded at $0.3 \mathrm{~V}(\mathbf{a})$, and $0.5 \mathrm{~V}(\mathbf{b})$, for different PtRu-based electrocatalysts/pure nanoparticles $(a)$, stabilized with $\mathrm{PMo}_{12}(b)$, stabilized with $\mathrm{PMo}_{12}$ and supported onto PDDA-MWCNTs (c). Electrolyte: $0.5 \mathrm{~mol} \mathrm{dm}^{-3} \mathrm{H}_{2} \mathrm{SO}_{4}$

determine their sizes and distribution. It is apparent from Fig. 2 that nanoparticles are quite uniformly distributed across the carbon nanotube carriers despite that fact that they show some tendency to form aggregates of the average size of $15-20 \mathrm{~nm}$.

Figure 1 (dashed lines) illustrates cyclic voltammetric responses recorded in the presence of ethanol of the PtRu system, bare and assembled onto MWCNTs before and after modification with $\mathrm{PMo}_{12}$. Each modification step should result in the increase of surface area. The highest current has been observed for the MWCNT-supported particles. Chronoamperometric curents, which have been recorded at different potentials (Fig. 3, Curves A, B) and during 1-h measurements at $0.4 \mathrm{~V}$ (Fig. 4) tend to increase significantly with each modification step. The enhancing effect of $\mathrm{PMo}_{12}$ on PtRu catalytic system during electrooxidation of ethanol was demonstrated in our previous paper [23]. In the present work, we have used polyoxometallate not only as a modifying agent but also as a tool to minimize tendency of $\mathrm{PtRu}$ nanoparticles to undergo agglomeration, namely through their stabilization. The observed increases in catalytic currents (Figs. 3 and 4) 


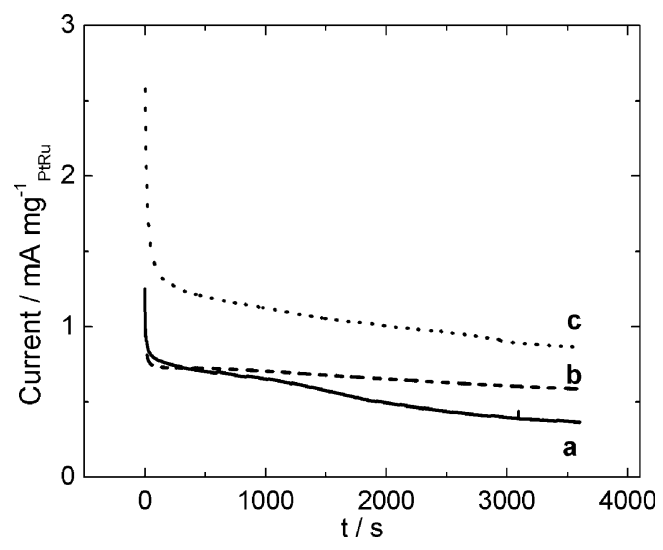

Fig. 4 Chronoamperometric one-hour electrooxidation of ethanol recorded at $0.4 \mathrm{~V}$ for different PtRu-based electrocatalysts/pure nanoparticles $(a)$, stabilized with $\mathrm{PMo}_{12}(b)$, stabilized with $\mathrm{PMo}_{12}$ and supported onto PDDA-MWCNTs (c). Electrolyte: $0.5 \mathrm{~mol} \mathrm{dm}^{-3} \mathrm{H}_{2} \mathrm{SO}_{4}$

shall be attributed to both changes in the chemical environment around catalytic centers and to changes in their morphology leading to increase of the overall catalytic surface. In particular, assembling of catalytic nanoparticles onto MWCNTs results in the further enhancement of their catalytic activity presumably through the significant increase of electrocatalytic surface area and better distribution of the active centers across the catalytic film.

PtRu Nanoparticles Synthesized onto PDDA-Functionalized MWCNTs

PDDA-functionalized MWCNTs has also been used as a template at which synthesis of PtRu nanoparticles has been performed. It was demonstrated before that PDDAMWCNTs could serve as a very useful support for synthesis of platinum and also palladium sheets [32]. Also, bimetallic PtRu nanoparticles were synthesized using similar method but instead PDDA 1-aminopyrene was used [17]. In the present work, we adapted the approach mentioned above to fabricate the PtRu alloyed nanoparticles on PDDA functionalized MWCNTs. Having in mind the positive role of the PDDA-functionalized MWCNTs on activity of commercial PtRu nanoparticles towards electrooxidation of ethanol, a similar enhancement effect on smaller, just synthesized, PtRu nanoparticles can be envisioned. The mechanism of fabrication of such PtRu nanoparticles has involved first self-assembling of negatively charged $\mathrm{Pt}$ precursors, $\mathrm{PtCl}_{6}{ }^{2-}$, on PDDAfunctionalized MWCNT, followed by the subsequent attachment of positively charged $\mathrm{Ru}$ precursors, $\mathrm{Ru}^{3+}$. Formation of the metallic nanoparticles on the carbon substrate has been achieved through reduction of the adsorbed precursors by ethylene glycol with the assistance of a microwave treatment.
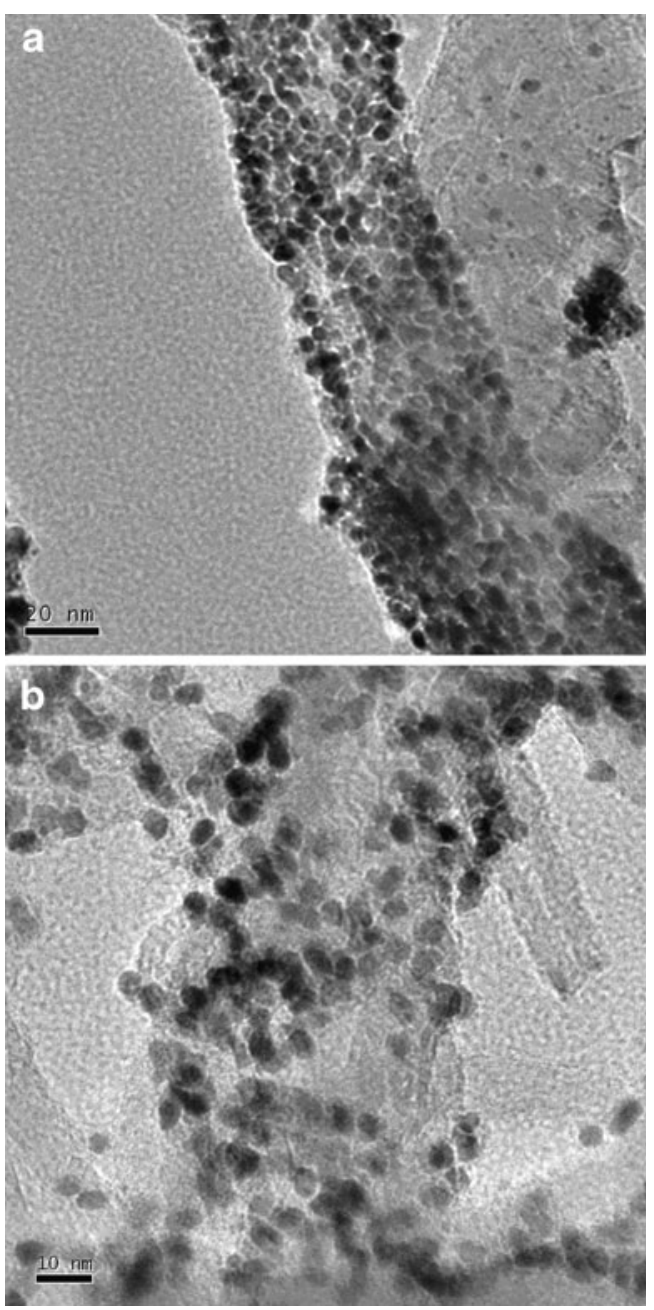

Fig. 5 a, b TEM images of $\mathrm{PtRu}$ nanoparticles synthesized on PDDA-MWCNTs

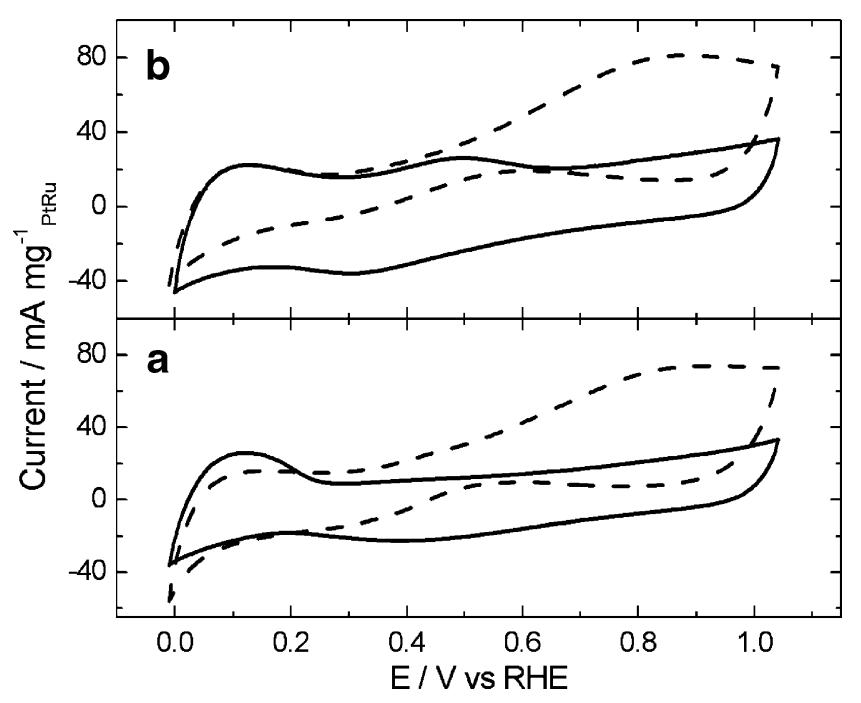

Fig. 6 Cyclic voltammograms of PtRu nanoparticles synthesized on PDDA-MWCNTs support (a), and subsequently stabilized with $\mathrm{PMo}_{12}(\mathbf{b})$, registered in $0.5 \mathrm{M} \mathrm{H}_{2} \mathrm{SO}_{4}$ (solid lines) and after addition of $0.5 \mathrm{~mol} \mathrm{dm}^{-3}$ ethanol (dashed lines) 

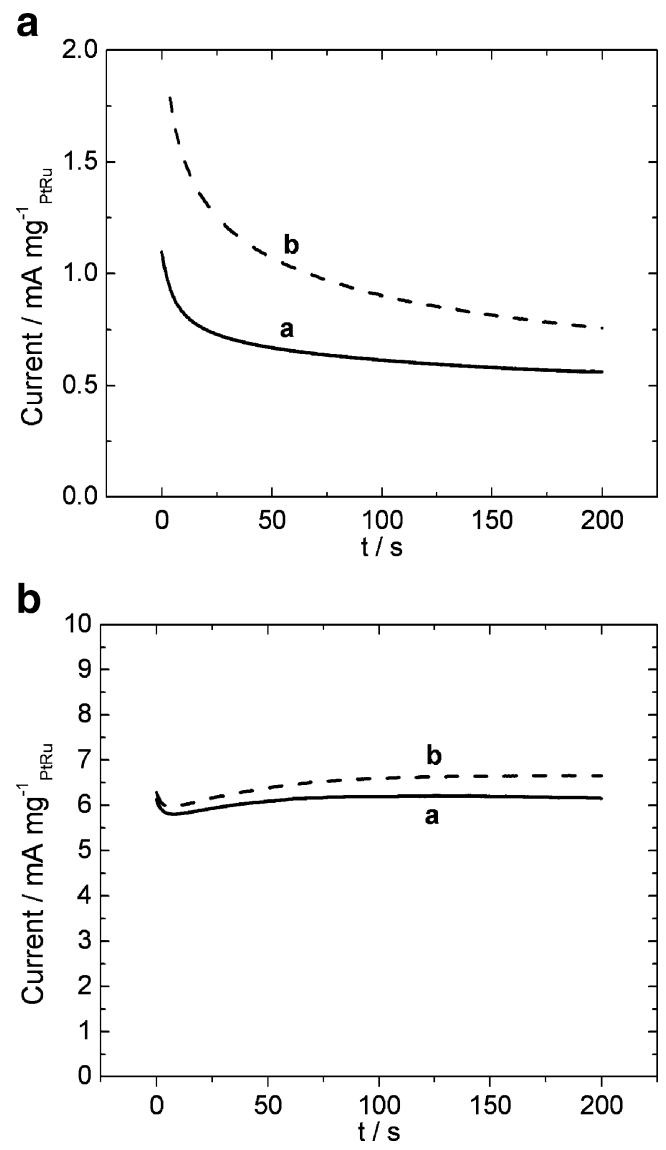

Fig. 7 Chronoamperometric electrooxidation of ethanol registered at $0.3 \mathrm{~V}$ (a) and $0.5 \mathrm{~V}$ (b) for PtRu nanoparticles synthesized on PDDAMWCNTs support (curves $a$ ), and additionally stabilized with $\mathrm{PMo}_{12}$ (curves b)

Morphology of PtRu nanoparticles synthesized on PDDA-functionalized carbon nanotubes was examined using transmission electron microscopy. It is evident from Fig. 5 that particles were successfully synthesized, and they are characterized by uniform size and distribution across the

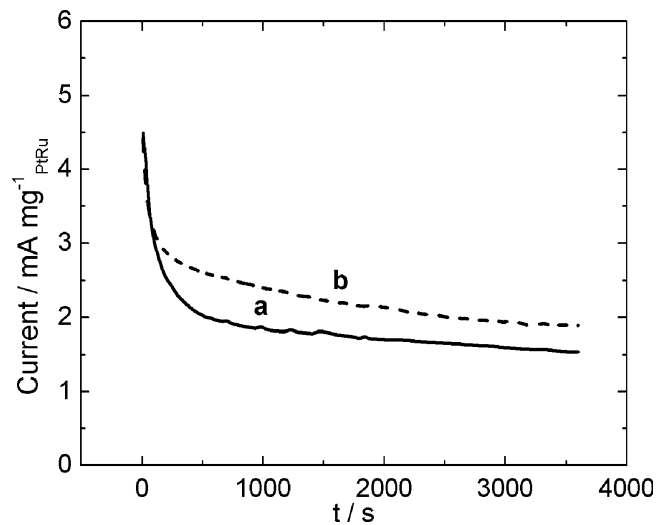

Fig. 8 Long-term chronoamperometric electrooxidation of ethanol recorded at $0.4 \mathrm{~V}$ for PtRu nanoparticles synthesized on PDDAMWCNTs support $(a)$ and additionally stabilized with $\mathrm{PMo}_{12}(b)$ Electrolyte: $0.5 \mathrm{~mol} \mathrm{dm}^{-3} \mathrm{H}_{2} \mathrm{SO}_{4}$

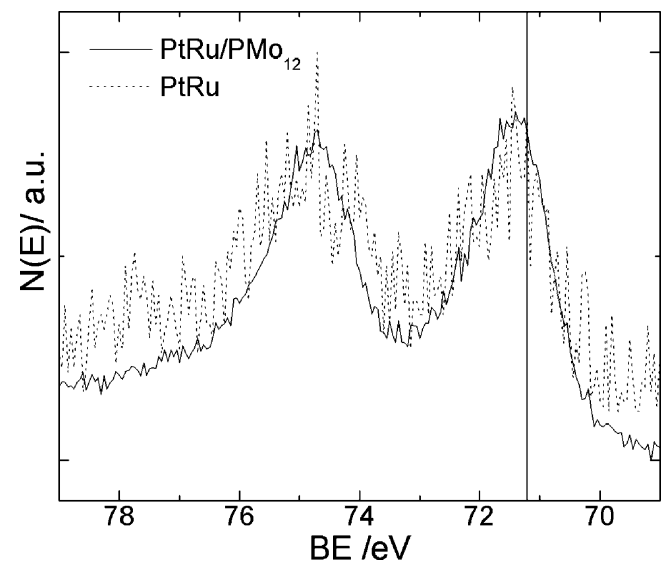

Fig. 9 XPS spectra of $\mathrm{Pt} 4 \mathrm{f}$ region for $\mathrm{PMo}_{12}$ (modified and unmodified) carbon-unsupported PtRu nanoparticles. BEs of Pt $4 \mathrm{f} 7 / 2$ electrons, for bulk, metallic Pt is marked with a vertical line

tubes. The average particle diameter can be estimated on the level 4-5 nm. Although most of carbon tubes were uniformly covered with PtRu nanparticles, there have been still some "bare regions" on the MWCNT surfaces most probably due to the absence of PDDA in such areas for the adsorption of precursors mentioned above.

Cyclic voltammetric characterization of PtRu/PDDA/ MWCNTs is illustrated in Fig. 6, Curve A (solid line). Further modification with $\mathrm{PMo}_{12}$ has been achieved through stabilization of PtRu/PDDA/MWCNTs with phosphomolybdate anions. Electrochemical response after introduction of heteropolyacid into the investigated system is shown in Fig. $6 \mathrm{~b}$ (solid line). Presence of the $\mathrm{PMo}_{12}$ is clearly visible from appearance of the peaks characteristic of the $\mathrm{PMo}_{12}$ redox reactions [22,33]. It was demonstrated before that $\mathrm{PMo}_{12}$ showed strong tendency to adsorb on carbon substrates $[33,34]$, realistically much more strongly than on metallic ones. In the presence of MWCNTs, larger amounts of phosphododecamolybdates exist at the electro-

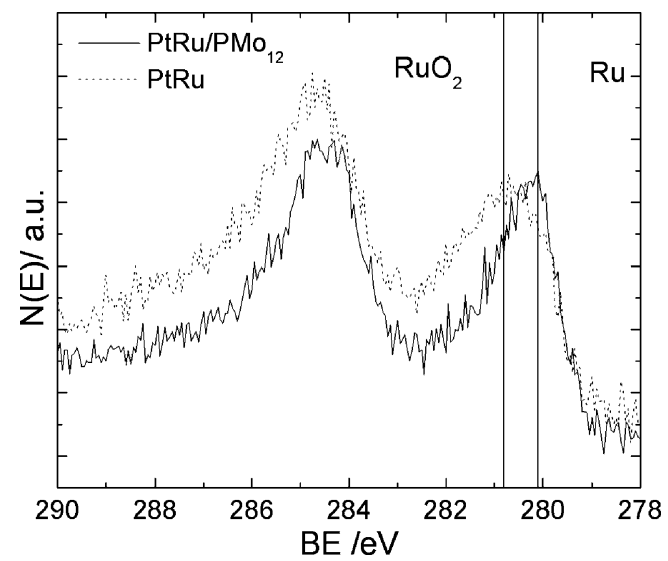

Fig. 10 XPS spectra of $\mathrm{Ru} 3 \mathrm{~d}$ region for $\mathrm{PMo}_{12}$ modified and unmodifed unsupported PtRu nanoparticles. BEs of $\mathrm{Ru} 3 \mathrm{~d} 5 / 2$ electrons, for bulk, metallic $\mathrm{Ru}$ and $\mathrm{RuO}_{2}$ are marked with vertical lines 
catalytic interface, i.e. in the vicinity of bimetallic PtRu active centers.

It is noteworthy that PtRu nanoparticles synthesized onto MWCNTs exhibit as a rule a superior performance during electrooxidation of ethanol both under voltammetric (Fig. 6, dashed lines) and chronoamperometric conditions (Figs. 7 and 8). Comparison of the behavior of commercial PtRu nanoparticles to the performance PtRu catalyst (at the same loading) synthesized on the MWCNTs implies much higher electrocatalytic activity of the latter system. It is reasonable to expect that PtRu nanoparticles fabricated on PDDAcovered MWCNTs are characterized by more uniform distribution and smaller sizes in comparison to commercial PtRu. In addition, large population of $\mathrm{PMo}_{12}$ (previously demonstrated to enhance activity of PtRu and PtSn [23]) existing at MWCNT-containing interface is also responsible for the electrocatalytic enhancement effect due to possible interactions between heteropolyacid and noble metal active centers. This effect is visible at all investigated potentials during chronoamperometric measurements (Figs. 7 and 8).

\section{XPS Study}

XPS core-level spectra have been recorded for unmodified and $\mathrm{PMo}_{12}$-modified unsupported PtRu samples. Based on comparison of the Pt $4 f$ spectra, no significant differences can be observed (Fig. 9). Pt is in the elemental state, and it is characterized by $\mathrm{Pt} 4 f_{7 / 2}$ binding energy (BE) electrons slightly (ca. $0.3 \mathrm{eV}$ ) higher than those for bulk Pt $(71.1 \mathrm{eV}$, marked with vertical line), and such phenomenon is often reported for nanoparticles containing Pt [35]. But the $\mathrm{Ru} 3 d$ region reveals a change in the Ru oxidation state (Fig. 10) from $\mathrm{RuO}_{2}$ for unmodified unsupported PtRu nanoparticles to metallic $\mathrm{Ru}$ in the presence $\mathrm{PMo}_{12}$ in a case of modified unsupported PtRu nanoparticles. It seems that $\mathrm{PMo}_{12}$ acts as a reducing agent. This observation is opposite to the recently observed oxidation of $\mathrm{Sn}$ in the case of PtSn nanoalloys modified with phosphomolybdates [23]. But it must be remembered that $\mathrm{PMo}_{12}$ (which undergoes multi-electron redox transitions) can act as an oxidizing or a reducing agent [18]. Thus, it can oxidize tin, but it cannot oxidize nobler ruthenium. In other words, $\mathrm{PMo}_{12}$ does not have sufficient oxidizing power to oxidize metallic Ru. Further, there are reasons to believe that in the presence of $\mathrm{PMo}_{12}$, interfacial reduction of ruthenium oxo-species occurs.

Obviously, the oxidation state of ruthenium affects significantly the electrocatalytic properties of bimetallic PtRu. When it comes to methanol electrooxidation, there is no agreement about the oxidation state of Ru existing in PtRu system and conditions for the most active electrocatalytic performance. It has been suggested that Ru may exist either in a form of Ru oxo species [36,37] or metallic Ru [38-42]. Of course, metallic $\mathrm{Ru}$ sites must be covered by some oxygen- containing surface groups (e.g., $-\mathrm{OH})$ to act effectively in the bi-functional mechanism. Our current data suggest that the reduced form of Ru enhances the catalytic activity of the system towards ethanol electrooxidation.

\section{Conclusions}

Modification of commercially available PtRu nanoparticles with $\mathrm{PMo}_{12}$, and their subsequent dispersion on the PDDAfunctionalized MWCNTs, leads to significant increase of the system's catalytic activity towards electrooxidation of ethanol. Functionalization of the MWCNTs with PDDA leads to the formation of highly active carbon-type supports (nanostructured carriers), as well as it permits uniform immobilization and distribution of noble metal catalytic nanoparticles at the electrocatalytic interface.

Alternatively, PtRu nanoparticles can be fabricated on PDDA-functionalized MWCNTs, and they are characterized by small sizes and uniform distribution across the supporting nanotubes. The overall increase of the systems' electrocatalytic properties may be achieved through interfacial modification and stabilization of both PtRu nanoparticles and carbon substrates with polyoxometallate $\left(\mathrm{PMo}_{12}\right)$. The role of $\mathrm{PMo}_{12}$ may include changes in morphology, sizeable increase of the electrochemical surface area as well as chemical or electronic interactions of polyoxometallate with ruthenium sites including possible chemical reduction of $\mathrm{Ru}$ oxo species to metallic $\mathrm{Ru}$.

Acknowledgements The support from Ministry of Science and Higher Education (Poland) under the grant Singapur/112/2007 and Agency for Science, Technology and Research (A*Star), Singapore under SERC grant 0721340054 is acknowledged. We also appreciate support from Foundation of Polish Science (FNP) under the Chair (Mistrz) Project.

Open Access This article is distributed under the terms of the Creative Commons Attribution Noncommercial License which permits any noncommercial use, distribution, and reproduction in any medium, provided the original author(s) and source are credited.

\section{References}

1. C. Lamy, S. Rousseau, E.M. Belgsir, C. Coutanceau, J.-M. Léger, Electrochim. Acta 49, 3901 (2004)

2. F.C. Simões, D.M. dos Anjos, F. Vigier, J.-M. Léger, F. Hahn, C. Coutanceau, E.R. Gonzalez, G. Tremiliosi-Filho, A.R. de Andrade, P. Olivi, K.B. Kokoh, J. Power Sources 167, 1 (2007)

3. H. Wang, Z. Jusys, R.J. Behm, J. Power Sources 154, 351 (2006)

4. E. Antolini, J. Power Sources 170, 1 (2007)

5. G.A. Camara, R.B. de Lima, T. Iwasita, Electrochem. Commun. 6, $812(2004)$

6. J.P.I. de Souza, S.L. Queiroz, K. Bergamaski, E.R. Gonzalez, F.C. Nart, J. Phys. Chem. B 106, 9825 (2002) 
7. V. Pacheco Santos, V. Del Colle, R. Batista de Lima, G. Tremiliosi-Filho, Langmuir 20, 11064 (2004)

8. F.L.S. Purgato, P. Olivi, J.M. Leger, A.R. de Andrade, G. Tremiliosi-Filho, E.R. Gonzalez, C. Lamy, K.B. Kokoh, J. Electroanal. Chem. 628, 81 (2009)

9. A. Oliveira Neto, R.R. Dias, Marcelo M. Tusi, M. Linardi, E.V. Spinacé, J. Power Sources 166, 87 (2007)

10. S.Q. Song, W.J. Zhou, Z.H. Zhou, L.H. Jiang, G.Q. Sun, Q. Xin, V. Leontidis, S. Kontou, P. Tsiakaras, Int. J. Hydrogen Energy 30, 995 (2005)

11. J. Mann, Nan Yao, A.B. Bocarsly, Langmuir 22, 10432 (2006)

12. J.-M. Léger, S. Rousseau, C. Coutanceau, F. Hahn, C. Lamy, Electrochim. Acta 50, 5118 (2005)

13. G. Tremiliosi-Filho, H. Kim, W. Chrzanowski, A. Wieckowski, B. Grzybowska, P.J. Kulesza, J. Electroanal. Chem. 467, 143 (1999)

14. M. Watanabe, S. Motoo, J. Electroanal. Chem. 60, 267 (1975)

15. A. Hamnett, Interfacial Electrochemistry-Theory Experiment and Applications (Marcel Dekker, New York, 1999), pp. 871-873

16. H.A. Gasteiger, N. Markovic, P.N. Ross, E.J. Cairns, J. Phys. Chem. 97, 12020 (1993)

17. S. Wang, X. Wang, S.P. Jiang, Langmuir 24, 10505 (2008)

18. M. Sadakane, E. Steckhan, Chem. Rev. 98, 219 (1998)

19. M. Chojak, M. Mascetti, R. Wlodarczyk, R. Marassi, K. Karnicka, K. Miecznikowski, P.J. Kulesza, J. Solid State Electrochem. 8, 854 (2004)

20. M. Chojak, A. Kolary-Zurowska, R. Wlodarczyk, K. Miecznikowski, K. Karnicka, B. Palys, R. Marassi, P.J. Kulesza, Electrochim. Acta 52, 5574 (2007)

21. P.J. Kulesza, M. Chojak, K. Karnicka, K. Miecznikowski, B. Palys, A. Lewera, A. Wieckowski, Chem. Mater. 16, 4128 (2004)

22. R. Wlodarczyk, R. Marassi, M. Chojak, K. Miecznikowski, A. Kolary, P.J. Kulesza, J. Power Sources 159, 802 (2006)

23. P.J. Barczuk, A. Lewera, K. Miecznikowski, A. Zurowski, P.J. Kulesza, J. Power Sources 195, 2507 (2010)

24. Shuangyin Wang, San Ping Jiang, T.J. White, Xin Wang, Electrochim. Acta (2009). doi:10.1016/j.electacta.2009.09.003

25. P.J. Kulesza, K. Karnicka, K. Miecznikowski, M. Chojak, A. Kolary, P.J. Barczuk, G. Tsirlina, W. Czerwiński, Electrochim. Acta 50, 5155 (2005)
26. K. Karnicka, M. Chojak, K. Miecznikowski, M. Skunik, B. Baranowska, A. Kolary, A. Piranska, B. Palys, L. Adamczyk, P.J. Kulesza, Bioelectrochemistry 66, 79 (2005)

27. S. Wang, S.P. Jiang, X. Wang, Nanotechnology 19, 265601 (2008)

28. Wagner CD, Naumkin AV, Kraut-Vass A, Allison JW, Powell JC, Rumble JR Jr, (2007) NIST Standard Reference Database 20, Version 3.4 (Web Version)

29. J.F. Moulder, W.F. Stickle, P.E. Sobol, K.D. Bomben, Handbook of X-ray Photoelectron Spectroscopy. A Reference Book of Standard Spectra for Identification and Interpretation of XPS Spectra (Physical Electronic, Inc., Eden Praire, 1995)

30. T. Iwasita, H. Hoster, A. John-Anacker, W.F. Lin, W. Vielstich, Langmuir 16, 522 (2000)

31. A. Lewera, M. Chojak, K. Miecznikowski, P.J. Kulesza, Electroanalysis 17, 1471 (2005)

32. Shuangyin Wang, San Ping Jiang, T.J. White, Xin Wang, Electrochim. Acta 55, 7652 (2010)

33. M. Skunik, M. Chojak, I.A. Rutkowska, P.J. Kulesza, Electrochim. Acta 53, 3862 (2008)

34. M. Skunik, B. Baranowska, D. Fattakhova, K. Miecznikowski, M. Chojak, A. Kuhn, P.J. Kulesza, J. Solid State Electrochem. 10, 168 (2006)

35. M.M. Schubert, M.J. Kahlich, G. Feldmeyer, M. Huttner, S. Hackenberg, H.A. Gasteiger, R.J. Behm, Phys. Chem. Chem. Phys. 3, 1123 (2001)

36. J.W. Long, R.M. Stroud, K.E. Swider-Lyons, D.R. Rolison, J. Phys. Chem. B 104, 9772 (2000)

37. D.R. Rolison, P.L. Hagans, K.E. Swider, J.W. Long, Langmuir 15, 774 (1999)

38. A. Lewera, W.P. Zhou, C. Vericat, J.H. Chung, R. Haasch, A. Wieckowski, P.S. Bagus, Electrochim. Acta 51, 3950 (2006)

39. A. Crown, H. Kim, G.Q. Lu, I.R. de Moraes, C. Rice, A. Wieckowski, J. New Mater. Electrochem. Syst. 3, 275 (2000)

40. R. Viswanathan, G.Y. Hou, R.X. Liu, S.R. Bare, F. Modica, G. Mickelson, C.U. Segre, N. Leyarovska, E.S. Smotkin, J. Phys. Chem. B 106, 3458 (2002)

41. K.W. Park, Y.E. Sung, J. Phys. Chem. B 109, 13585 (2005)

42. J.B. Goodenough, A. Hamnett, B.J. Kennedy, R. Manoharan, S.A. Weeks, J. Electroanal. Chem. 240, 133 (1988) 